\title{
Homogeneity Studies on Human Growth Hormone
}

\author{
BY W. M. HUNTER* \\ Scientific Staff, Imperial Cancer Research Fund, Lincoln's Inn Fields, London, W.C. 2
}

(Received 3 May 1965)

\begin{abstract}
1. Human growth hormone preparations (Raben) have been found to contain $10-40 \%$ of denatured growth hormone as shown by radioimmunoassay, reaction of radioiodinated subfractions with antiserum to whole growth hormone, and amino acid analysis, and confirmed by bioassay using the tibia test. 2 . The altered fraction was more electronegative than the intact hormone on starch-grain electrophoresis in barbitone buffer, $\mathrm{pH} 8 \cdot 6$. Some heterogeneity of the active material was detectable in simple buffer extracts of a single acetone-stored pituitary gland. 3. The inert fraction was more completely separated from the active hormone as an unretarded fraction from Sephadex G-200 columns with a borate buffer. This separation was due to aggregation of the denatured growth hormone in borate buffer. The active fraction from the Sephadex column still contained some inert material and the amount of this remaining varied considerably between different batches of growth hormone. 4. The radioimmunoassay procedure detects only the immunologically and biologically intact fraction.
\end{abstract}

Human growth hormone prepared by the method of Raben (1959) from pituitary glands stored in acetone has been widely used as antigen and standards for immunological assays based upon haemagglutination inhibition (Read \& Stone, 1958; Read \& Bryan, 1960) and for the recent, more specific and precise, radioimmunoassays (Hunter \& Greenwood, 1962, 1964; Glick, Roth, Yalow \& Berson, 1963). Raben (1959) had suggested that solubility studies and poor recoveries, from a chromatographic system with CM-cellulose in acetic acid-calcium chloride solutions, indicated some heterogeneity. This preparation has been shown to be heterogeneous on starch gel (Ferguson \& Wallace, 1961 ; Barrett, Friesen \& Astwood, 1962) and on immunoelectrophoresis (Boucher, 1960; Grumbach \& Kaplan, 1962), though the subfractions were antigenically similar. The present study was undertaken to examine the validity of using this preparation for labelling with radioiodine in a radioimmunoassay since the specificity of this method depends upon the homogeneity of the hormone preparation used for this purpose. A preliminary report has already appeared (Hunter, 1963).

\section{EXPERIMENTAL}

\section{Materials}

Human pituitary glands were kindly supplied by Dr J. Clark of the New Sussex Hospital, Brighton, and were stored

* Present address: Medical Research Council Clinical Endocrinology Research Unit, Edinburgh, 1. and transported in acetone and dried in air and then in vacuo on receipt.

The molarities for barbitone, borate and phosphate buffers were those of the respective acids, and were prepared by titrating the acid with $\mathrm{NaOH}$ to the required $\mathrm{pH}$.

'Laboratory standard' means ICRF batch 3 human growth hormone unfractionated.

\section{Methods}

Growth hormone was prepared by the method of Raben (1959) and designated ICRF batch 1, 2, 3 etc.

Barbitone buffer extract of human pituitary gland. An aqueous alkaline extract was obtained from a single human pituitary gland by homogenization in $2 \mathrm{ml}$. of water and addition of $0.2 \mathrm{ml}$. of $0.1 \mathrm{~N}-\mathrm{NaOH}$. This was immediately diluted with $10 \mathrm{ml}$. of $0.07 \mathrm{~m}$-barbitone buffer, $\mathrm{pH} 8 \cdot 6$, and then centrifuged at $2000 \mathrm{~g}$ for $30 \mathrm{~min}$.

Ultracentrifuge studies. The Beckman Spinco model E analytical ultracentrifuge was used.

Electrophoresis. (i) Free-boundary electrophoresis was carried out with the Beckman Spinco model $\mathbf{H}$ apparatus. (ii) Starch-grain electrophoresis was carried out by using the method of Kunkel \& Slater (1952) as used for growth hormone ( $\mathrm{Li} \&$ Papkoff, 1956) with a barbitone-NaCl buffer, $\mathrm{pH} \mathrm{8.4,} \mathrm{for} \mathrm{the} \mathrm{starch} \mathrm{slurry,} \mathrm{the} \mathrm{wick} \mathrm{and} \mathrm{electrode}$ compartments. A constant voltage gradient of $5 \mathrm{v} / \mathrm{cm}$. was used across $40 \mathrm{~cm}$.-long glass troughs, semi-circular in section with cross-sectional area $1 \mathrm{~cm} .{ }^{2}$ or $6 \mathrm{~cm} .{ }^{2}$. After electrophoresis the protein was eluted from the support medium with $\mathrm{NaCl}$ solution $(0.9 \%)$ and the starch grains were then removed by centrifugation.

Gel filtration on Sephadex columns. Sephadex G-25 and G-50 columns were packed as recommended by the manufacturers. Sephadex G-200 for columns was stirred for $24 \mathrm{hr}$., the slurry washed twice to remove fines and the 
column was then packed with a thick slurry (Flodin, 1961). All these steps were carried out in the buffer to be used for gel filtration. The Sephadex was allowed to settle in the columns for at least $16 \mathrm{hr}$. before a further wash for $24 \mathrm{hr}$. was started. The inclusion of $0.5 \mathrm{~g}$. of Sephadex G-25 above the sintered glass disk prevented a slow loss of Sephadex G-200 from these columns. Samples of protein were applied to the column and, after their entry into the gel, two washes, each of the same volume as the sample, were applied. A 'head' of $100 \mathrm{~cm}$. of buffer was then applied by filling an extension tube above the column. Fractions were collected by a siphon system by using the Central fraction collector.

Estimation of protein. (i) By measurement of the extinction at $280 \mathrm{~m} \mu$ or, where material was scarce, at $215 \mathrm{~m} \mu$ with the Uvispek spectrophotometer with quartz cells of $1 \mathrm{~cm}$. light-path. (ii) For protein eluted from starch-grain electrophoresis troughs and from Sephadex columns in barbitone buffer, estimation was by the method of Lowry, Rosebrough, Farr \& Randall (1951).

Method of dissolving growth hormone. The growth hormone was stirred until thoroughly wetted with water $(0.5$ or $1 \mathrm{ml}$.), after which $\mathrm{N}-\mathrm{NaOH}(0.05$ or $0.1 \mathrm{ml}$.) was added, when the solution became clear. Immediately thereafter sufficient buffer was added to bring the growth hormone to the required concentration.

\section{RESULTS}

Gel filtration on Sephadex columns. Human growth hormone is eluted as a single peak immediately after the passage of $V_{0}$ from columns of Sephadex G-25 and G-50 in phosphate, barbitone and borate buffers. This was also found for G-50 columns in acetic acid $(0 \cdot 1 \mathrm{M})$, whereas Irie \& Barrett (1962) found two components in such a system. From Sephadex G-200 columns in 0.12M-barbitone, pH 8.6, and $0.05 \mathrm{M}$-sodium phosphate $\mathrm{pH} \mathrm{7.5}$, these preparations are retarded but appear in the eluates as a single component. These properties are to be expected of a protein of mol.wt. $20000-30000$ as indicated by ultracentrifugation studies $[29000$ (Squire \& Pedersen, $1961 ; 21500(\mathrm{Li}, 1964)]$ on human growth hormone prepared by the method of Li \& Papkoff (1956).

Growth hormone (ICRF batch 4), when applied to a Sephadex G-200 column (4 g.) in borate ( $0.05 \mathrm{M})-$ potassium chloride $(0.05 \mathrm{M}), \mathrm{pH} 8.6$, showed the distribution indicated in Fig. 1. An identical pattern was found for portions of the same solution of human growth hormone applied to the column after (a) solution of the hormone in the usual way with the help of alkali, (b) passage through a Sephadex G-25 column in borate $(0.05 \mathrm{M})$-potassium chloride $(0.05 \mathrm{M}), \mathrm{pH} \mathrm{8.6,}(c)$ preparation as for $(b)$ but subsequently allowed to stand for $16 \mathrm{hr}$. at 2-4 $4^{\circ}$. The distribution was also constant for quantities of the same batch of growth hormone over the range $2-100 \mathrm{mg}$. applied to the column. Fig. 2 shows the distribution of separated subfractions prepared by dialysis and freeze-drying of the eluates of the

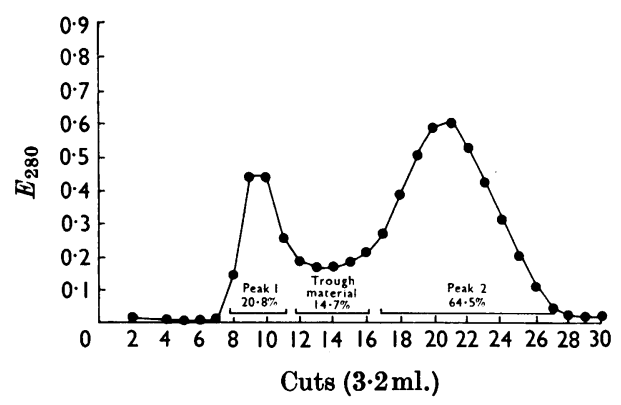

Fig. 1. Gel filtration of growth hormone (ICRF batch 4, $24 \cdot 3 \mathrm{mg}$.) on a Sephadex G-200 column (4 g., diameter $2 \mathrm{~cm}$.) in borate $(0.05 \mathrm{M})-\mathrm{KCl}(0.05 \mathrm{M}), \mathrm{pH} 8.6$.

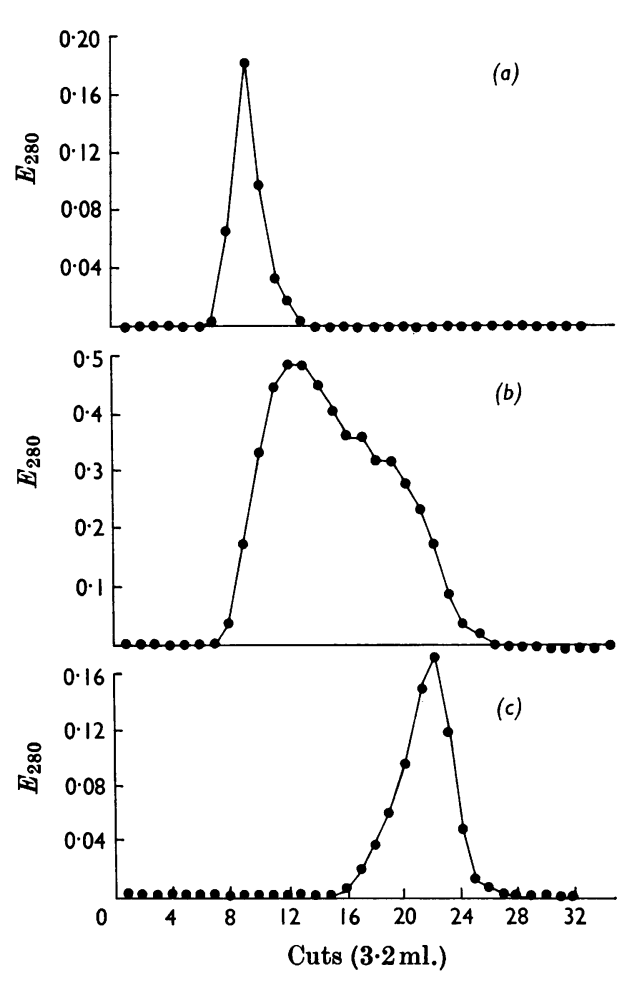

Fig. 2. Re-run of separated fractions of growth hormone by gel filtration on a Sephadex G-200 column (4 g., diameter $2 \mathrm{~cm}$.) in borate $(0.05 \mathrm{M})-\mathrm{KCl}(0.05 \mathrm{M}), \mathrm{pH} 8 \cdot 6$. (a) Peak 1 material; (b) trough material; (c) peak 3 material.

experiment shown in Fig. 1, when each of these was applied individually to the same column. It will be seen that the two main subfractions reappeared in their distinctive positions. Some of the intermediate 'trough' material, however, appeared earlier in the eluates, in a position corresponding to peak 1 
Table 1. Distribution of protein (by $E_{280}$ ) and growth hormone by immunoassay after gel filtration of growth hormone

Growth hormone (ICRF batch 4, 28.5 mg.) in Sephadex G-200 in borate (0.05 M)-KCl (0.05 M), pH 8.6, was used.

$\begin{array}{ccc} & \text { Trough } & \text { Peak } 2 \text { except } \\ \text { Peak } 1 & \text { material tube } 22 \text { (tubes }\end{array}$

(tubes 8-11)

$6 \cdot 0$

0.72

$0 \cdot 12$

tube 22 (tubes
Protein (mg. by $E_{280}$ )

Growth hormone by

immunoassay (mg.)*

Activity/mg. of protein (potency)*

* Obtained with growth hormone, ICRF batch 4 (unfractionated), as standard.

Table 2. Radioimmunoassay and tibia line assay of fractions from growth hormone separated by gel filtration

Gel filtration in Sephadex G-200 in borate (0.05 M)-KCl $(0.05 \mathrm{~m}), \mathrm{pH} 8 \cdot 6$, was used. For both assays results are expressed as percentage of potency of the starting material; growth hormone ICRF batch 3 was used. The tibia line assay was done by Miss H. E. C. Cargill Thompson. Figures in parentheses give the fiducial limits for $P \mathbf{0 . 0 5}$.

$\begin{array}{ccc} & \begin{array}{r}\text { Radioimmunoassay } \\ (\%)\end{array} & \begin{array}{c}\text { Tibia line assa } \\ (\%)\end{array} \\ \text { Peak 1 } & 18 \cdot 4 & 19 \cdot 7 \\ & & (13-30) \\ \text { Peak 2 } & 120 \cdot 0 & 142 \cdot 0 \\ & & (111-228)\end{array}$

material. Table 1 shows the results of assaying, by the radioimmunoelectrophoretic procedure, the subfractions from the experiment shown in Fig. 1. Quantitative recoveries of protein by extinction at $280 \mathrm{~m} \mu$ and of growth hormone by immunoassay were obtained. The individual assay of the single tube no. 22 was carried out to assess the homogeneity of peak 2. The results indicate that $91.4 \%$ of the total immunologically determined growth hormone was present in peak 2, which represented $61.4 \%$ of the total protein present in the starting material. It will be seen that the eluted protein represents a continuum with potencies increasing with retardation by the gel column. Material from the later part of peak 2 (tube no. 22) was marginally more potent than the pooled peak. However, this difference was so much smaller than that between pooled peak 2 and each of the other subfractions that in future experiments peak 2 material was not subdivided.

In a second experiment with growth hormone ICRF batch 3, on the same column, a similar distribution was found. The two main fractions, peaks 1 and 2, were separately dialysed and freeze-dried and then assayed by the radioimmunoassay and by bioassay using the tibia test. This assay was carried

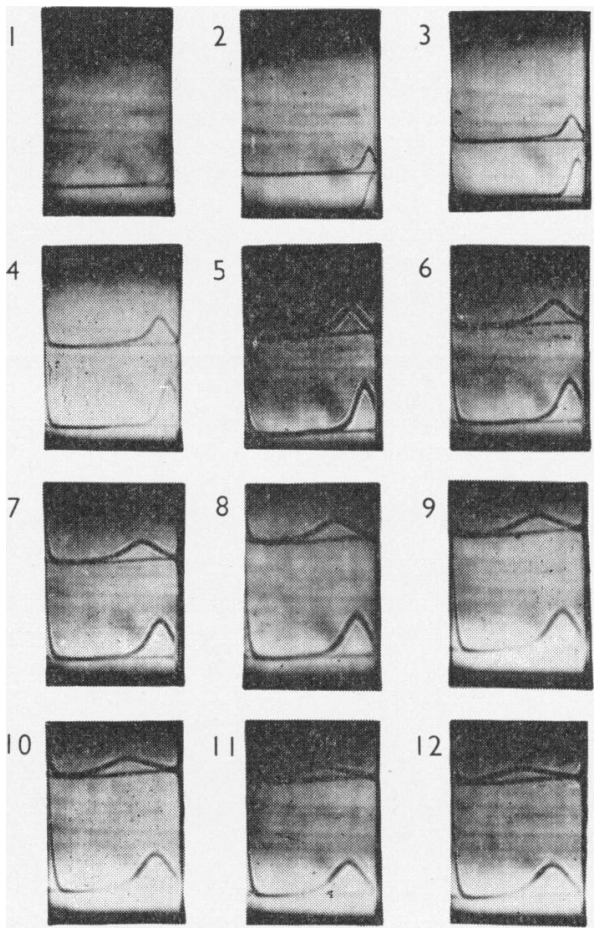

Fig. 3. Ultracentrifuge schlieren diagrams of Sephadex subfractions in borate $(0.05 \mathrm{M})-\mathrm{KCl}(0.05 \mathrm{M})$, pH 8.6, with the double-sector cell. For each pair the upper diagram is peak 1 material and the lower one is peak 2 .

out by Miss H. E. C. Cargill Thompson at the Medical Research Council Clinical Endocrinology Research Unit, Edinburgh. The results are shown in Table 2. It will be seen that the two assays agree excellently: the activities of both subfractions expressed as potencies of the initial starting material were well within the experimental error of the bioassay. Most of the activity both by immunological and biological assay is found in peak 2 . 
A portion of the same solution of growth hormone (ICRF batch 4) (in borate-potassium chloride) as that applied to the column for the experiment shown in Fig. 1 was analysed in the Spinco model $\mathrm{E}$ ultracentrifuge. The schlieren diagram showed a

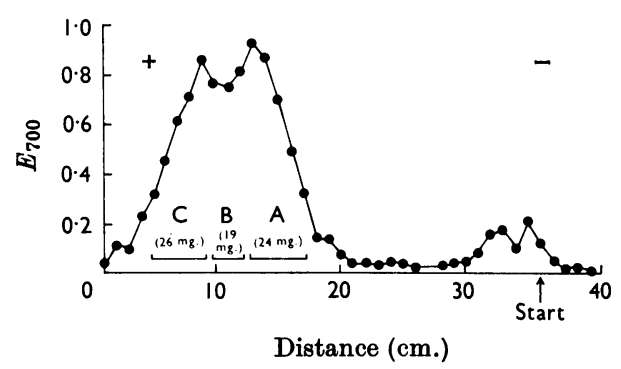

Fig. 4. Starch-grain electrophoresis of growth hormone (ICRF batch 2). Distribution of protein (estimated by the method of Lowry et al. 1951) after elution from $1 \mathrm{~cm}$. cuts. Starch slurry and electrode vessels buffer: barbitone- $\mathrm{NaCl}$, I0.1, pH8.4. A constant voltage gradient $(5 \mathrm{v} / \mathrm{cm}$.) was applied for $48 \mathrm{hr}$. single symmetrical component and from the data obtained $S$ value $2.6 \mathrm{~s}$ was calculated. This is in good agreement with the value $S_{20, w} 2 \cdot 5 \mathrm{~s}$ found by Squire \& Pedersen (1961) for human growth hormone prepared by the method of Li \& Papkoff (1956) in a phosphate buffer, pH 2.38. Fig. 3 shows the schlieren diagrams obtained when solutions of peaks 1 and 2 material, each in borate-potassium chloride, were ultracentrifuged by using the double-sector cell. Peak 1 material appears as a more heterogeneous and faster sedimenting component than peak $2 . S_{20}$ values (uncorrected) 4.5 and 2.0 s were calculated for peaks 1 and 2 respectively. This would imply a much smaller size difference between peaks 1 and 2 material than that expected from their widely different behaviour on Sephadex G-200 in the same buffer. No explanation for this difference is offered but it is clear that both the ultracentrifuge and Sephadex reveal aggregation of the denatured growth hormone in the borate buffer. It is possible also that borate may alter the properties of the Sephadex since borate is known to show anomalous behaviour on these columns (Gelotte, 1960). However, the emergence of intact growth hormone

Table 3. Amino acid composition of human growth hormone

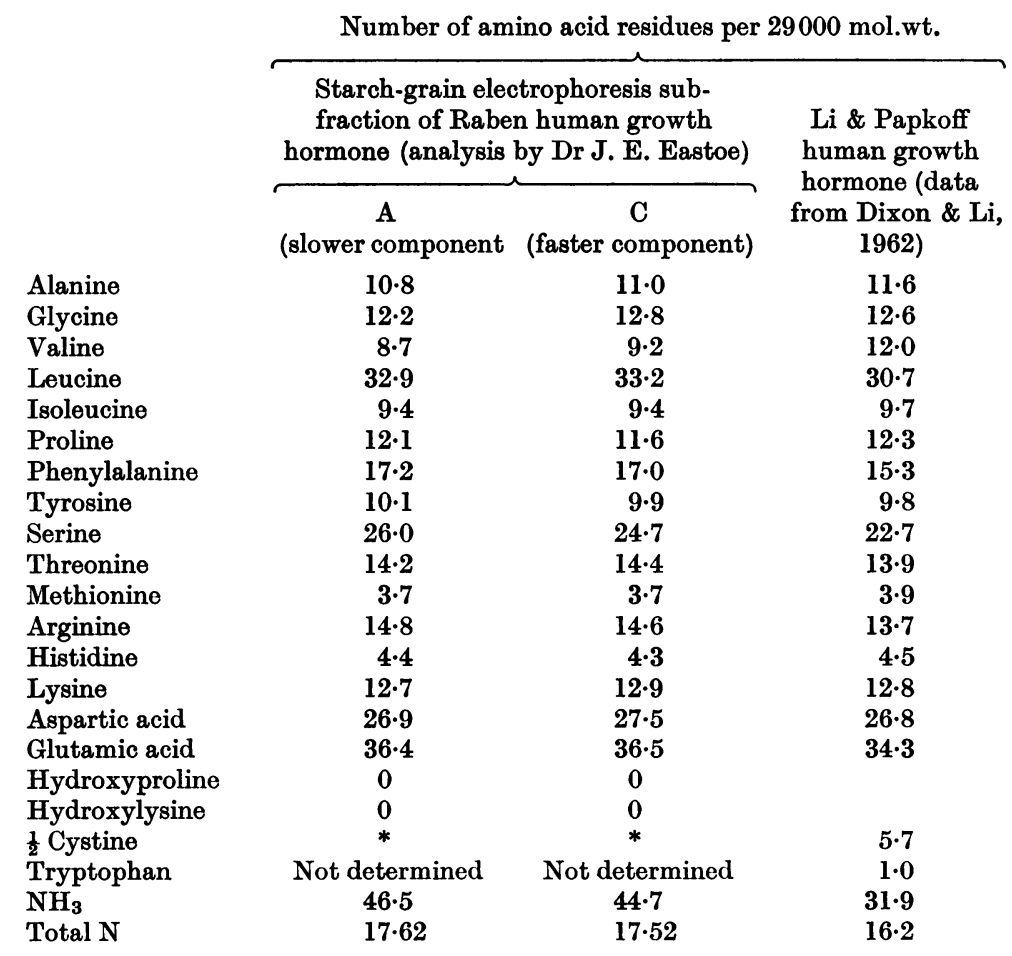

* A very small quantity of ninhydrin-positive material having zero hold-up volume was detected for both peaks. This was probably cysteic acid arising by oxidation of cystine. 
at identical times in the eluates of Sephadex G-200 columns in borate, barbitone and phosphate speaks against this.

Electrophoresis. Growth hormone (ICRF batch 5) was subjected to electrophoresis in barbitone buffer,

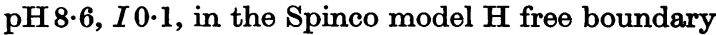
apparatus at $1^{\circ}$. In this experiment a $2 \mathrm{ml}$. cell was used, and a current of $3 \mathrm{~mA}$ was passed for $37.2 \mathrm{~min}$. This series indicated a homogeneous protein of approximate electrophoretic mobility $-3.65 \times 10^{5}$ $\mathrm{cm} .2 / \mathrm{v} / \mathrm{sec}$. However, with starch-grain electrophoresis (Kunkel \& Slater, 1952) in a sodium chloride-diethylbarbiturate buffer, $\mathrm{pH} 8 \cdot 4, I 0 \cdot 1$, run for $48 \mathrm{hr}$. at a constant gradient of $5 \mathrm{v} / \mathrm{cm}$., Raben growth hormone (ICRF batch 2) migrated as a broad double peak (Fig. 4). The distribution suggests the partial separation of a slow component from a faster one which itself is still heterogeneous.

Fraction A, representing the slowest part of the material, and fraction $C$ (the fastest components) (Fig. 4) were each pooled, dialysed and freeze-dried and then subjected to amino acid analysis. This was carried out by Dr J. E. Eastoe of the Department of Dental Science, Royal College of Surgeons, London, who used the method of Moore \& Stein (1951)

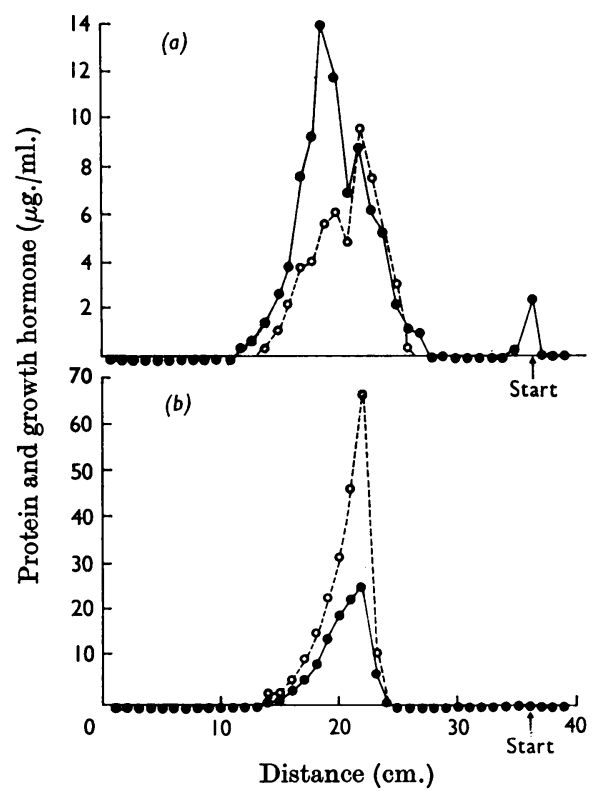

Fig. 5. Starch-grain electrophoresis of growth hormone subfractions prepared by gel filtration on Sephadex G-200. (a) Peak 1 material; (b) peak 2 material. Distribution of protein (estimated by the method of Lowry et al. 1951) (—- ) and growth hormone (by immunoassay) (O-after elution from $1 \mathrm{~cm}$. cuts. Barbitone buffer, $I 0 \cdot 1, \mathrm{pH} 8 \cdot 6$, was used, and a constant voltage $(5 \mathrm{v} / \mathrm{cm}$.) was applied for $40 \mathrm{hr}$. slightly modified by Eastoe (1955). The results of this analysis are given in Table 3 together with the published analysis by Dixon \& $\mathrm{Li}$ (1962) for the $\mathrm{Li} \&$ Papkoff (1956) preparation. The estimates for individual amino acids in fractions $\mathbf{A}$ and $\mathbf{C}$ are within the experimental error of the method, with the exception of serine, which is higher in fraction $A$, and amide nitrogen, which was significantly lower in fraction $C(\mathbf{4 4 . 7}$ residues $/ 29000 \mathrm{~mol}$.wt.) than in fraction $A(\mathbf{4 6 . 5}$ residues). This difference implies the presence of two more free carboxyl groups in fraction $\mathrm{C}$ than in fraction $\mathrm{A}$ and this could account for the difference in electrophoretic mobility. In a later series of experiments peaks 1 and 2 from the Sephadex G-200 column in boratepotassium chloride were subjected to starch-grain electrophoresis. Fig. 5 shows the distribution of protein (by the method of Lowry et al. 1951) and of growth hormone by radioimmunoassay. There is relatively more electronegative material in the less active peak 1 fraction. The activity, however, in this fraction is concentrated in the more electropositive material. The activity in peak 2 also shows a skewed distribution and both experiments suggest that there is still some heterogeneity of charge in the active material. Fig. 6 shows the distribution of protein and of growth hormone activity by immunoassay when a simple barbitone extract from a single whole acetone-dried pituitary gland was subjected to electrophoresis in the same starchgrain system. The skewed distribution of immunological activity suggests that at least some heterogeneity of charge in the active material is present in the acetone-stored gland.

Meisinger, Cirillo, Davis \& Reisfeld (1964) have recently shown that the polyacrylamide gelelectrophoresis subfractions of human growth hormone prepared by the method of Reisfeld,

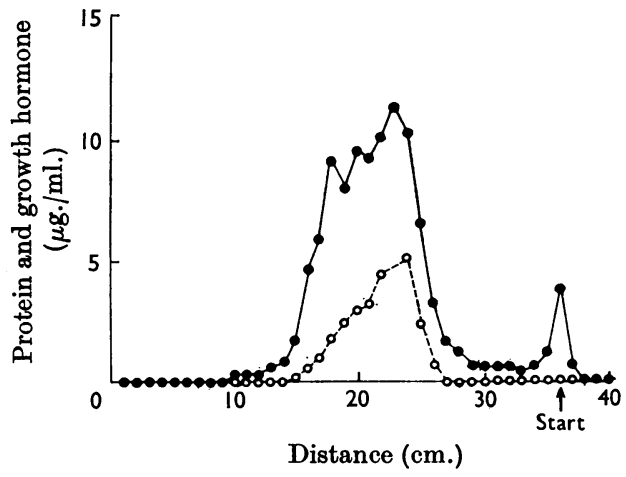

Fig. 6. Starch-grain electrophoresis of a barbitone buffer extract of a single human pituitary gland. Conditions and estimations were as for Fig. 5. 
Hallows, Williams, Brink \& Steelman (1963) were identical in amino acid analysis. Because of scarcity of material in their faster moving band, they were unfortunately unable to determine amide ammonia in this fraction, though they postulate that its increased mobility could be due to deamidation. These workers found 27 ammonia residues $/ 29000$ mol.wt. in their slower main band. This agrees fairly well with the figure 32 found by Dixon \& $\mathrm{Li}$ (1962) for their unfractionated growth hormone. No explanation for the discrepancy between these and the present figures (46.5 and 44.7 ammonia residues $/ 29000 \mathrm{~mol}$.wt.) for the two subfractions of Raben growth hormone can at present be suggested.

Nature of subfractions from Sephadex G-200 columns in borate. Although amino acid analysis was not carried out on subfractions from the Sephadex G-200 column the association of increased electronegativity with early elution from this column as well as with only minor differences in amino acid analysis implies that the components from the Sephadex column would differ little in amino acid analysis. The finding that the trough material can appear as peak 1 material when reapplied to the column shows that trough material can become altered to form peak 1 material. Evidence was therefore sought to ascertain whether the amount of inert peak 1 material in growth hormone preparations could be increased and whether the active peak 2 material could be converted into the inert peak 1 substance. Accordingly, a portion of the acetic acid-acetone extract of whole acetone-dried pituitaries was taken as a side fraction from the main preparation of growth hormone ICRF batch 4, after this had been cooled to room temperature and filtered. The side fraction was reheated to $70^{\circ}$ and maintained at this temperature for $30 \mathrm{~min}$. and then cooled rapidly in an ice bath to room temperature. The preparation was then continued by the usual method (Raben, 1959) and the final product designated ICRF batch 4 b. Fig. 7 shows the elution pattern for this preparation for the G-200 column in borate-potassium chloride and this may be compared with that of the main batch 4 (Fig. 1). Batch $4 \mathrm{~b}$ possessed $66.4 \%$ of the potency of batch 4 by radioimmunoassay. This was associated with an increase of $1.5 \%$ of peak 1 material and of $14 \%$ of trough material. Assuming all this altered material had also completely lost activity, it is apparent that there is some inactivation associated with material which still appears in the peak 2 position. However, prolonged treatment with hot acetic acid-acetone had resulted in a transformation of peak 2 material into material appearing earlier in the column eluates. The presence of marginal damage in 131I-labelled growth hormone preparations made by using excessive amounts (4 mc) of the ${ }^{131}$ I preparation IBS/3 (The

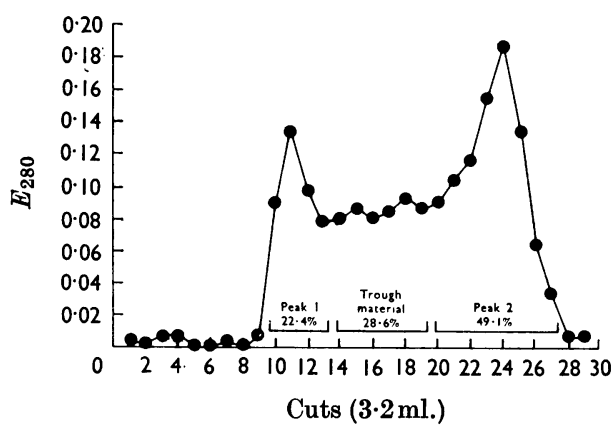

Fig. 7. Gel filtration of side fraction (4b) of growth hormone (see text) on Sephadex G-200 in borate $(0.05 \mathrm{M})-\mathrm{KCl}(0.05 \mathrm{M})$, pH 8.6; $6 \cdot 3 \mathrm{mg}$. of batch $4 \mathrm{~b}$ was applied to the column (4g., diameter $2 \mathrm{~cm}$.).

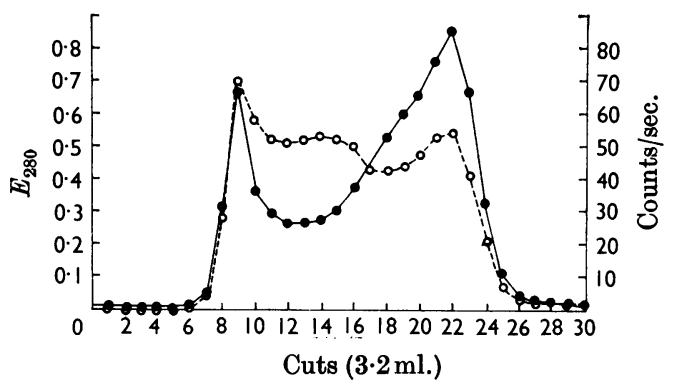

Fig. 8. Gel filtration of growth hormone (batch 4) (100 mg.) together with a trace amount of 131I-labelled growth hormone $(400 \mu \mathrm{c} / \mu \mathrm{g}$.$) on Sephadex G-200 in borate (0.05 \mathrm{M})-$ $\mathrm{KCl}(0.05 \mathrm{M}), \mathrm{pH} 8 \cdot 6$. - , Distribution of protein by $E_{280}$; O---O, distribution of radioactivity.

Radiochemical Centre) has been noted by Greenwood, Hunter \& Glover (1963). Fig. 8 shows the distribution of this damaged radioiodinated growth hormone run with carrier (unlabelled) growth hormone of the same batch. The relative increase in peak 1 and trough material in the iodinated material is apparent, indicating again an association of inactivation with early appearance from this column.

Experiments with radioiodinated growth hormone subfractions. In an attempt further to investigate the nature of peak 1 material, this fraction was labelled with radioiodine (by the method of Greenwood et al. 1963) and the reaction of this labelled material with antiserum to whole growth hormone (M.R.C. preparation Rl) was studied. It was important for this experiment that no fortuitous fractionation of growth hormone subfractions should occur during the labelling procedure. This could occur since peak 1 material had been found to show 


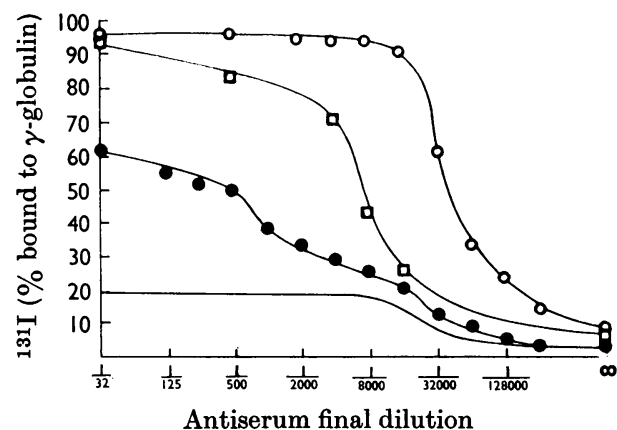

Fig. 9. Effect of dilution of anti-growth hormone serum on the percentage of antigen bound to $\gamma$-globulin (assessed from radioactivity determinations after electrophoresis of the incubated samples). $0,2 \cdot 0 \mathrm{~m} \mu \mathrm{g}$. of $131 \mathrm{I}$-labelled peak 2 ; ๑, $20.0 \mathrm{~m} \mu \mathrm{g}$. of ${ }^{131} \mathrm{I}$-labelled peak $1 ; \square, 20.0 \mathrm{~m} \mu \mathrm{g}$. of $131 \mathrm{I}$ labelled growth hormone (unfractionated), ICRF batch 4; - theoretical line for $4 \mathrm{~m} \mu \mathrm{g}$. of ${ }^{131} \mathrm{I}$-labelled peak 2 plus $80 \%$ of immunologically inert material.

a much greater tendency to adsorb to glass and to Sephadex than the active peak 2 material. Therefore $100 \mu \mathrm{g}$. of the protein in $0.1 \mathrm{ml}$. rather than the normal $5 \mu \mathrm{g}$. in $0.025 \mathrm{ml}$. was used to minimize adsorption to the glass tube in which iodination was carried out; also the Sephadex G-50 column step for separating the 131I-labelled protein from unreacted iodide and other low molecular weight reagents was omitted. These reagents were diluted (1/2500) before incubation with antiserum. The cellulose acetate electrophoretic system used for the separation of antibody-bound and free 131Ilabelled growth hormone was also used to remove unchanged [131I]iodide, which under the conditions used (Hunter \& Greenwood, 1964) migrates off the strip into the wick compartments of the electrophoresis tank. (In a control experiment in which protein was omitted from such an iodination mixture $99.6 \%$ of the $131 \mathrm{I}$ applied to the cellulose acetate was so removed from the strip.) Fig. 9 shows the results of this experiment. For comparison curves obtained with 2.0 and $20.0 \mathrm{~m} \mu \mathrm{g}$. of 131I-labelled peak 2 as antigen are included, and also the theoretical line obtained by assuming 131Ilabelled peak 1 was $80 \%$ of inert material and $20 \%$ of intact growth hormone (i.e. $4 \mathrm{~m} \mu \mathrm{g}$.). The curve determined experimentally shows inflexions at $1 / 750$ and $1 / 16000$ dilutions of antiserum, the latter coinciding with the theoretical line inflexion for the growth hormone antiserum system with $4 \mathrm{~m} \mu \mathrm{g}$. of growth hormone. The results suggest a threecomponent system: a component of weak avidity giving an inflexion at $1 / 750$ and comprising $40 \%$ of peak 1; a component of avidity equivalent to growth hormone and comprising $20 \%$ of peak 1 ; a

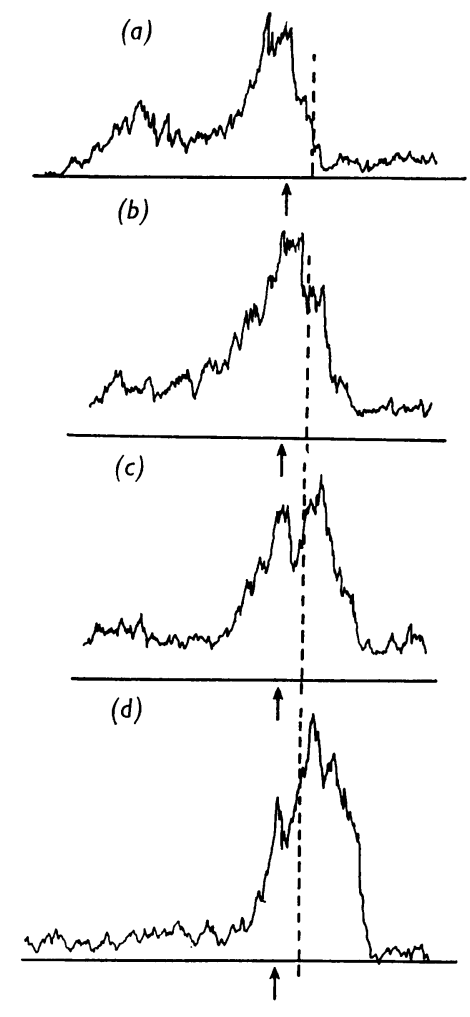

Fig. 10. Electrophoretic separation of 'bound' and 'free' 131I-labelled growth hormone peak 1 component $(20 \mathrm{~m} \mu \mathrm{g}$.) after incubation with different dilutions of antiserum: (a) blank: no antiserum; (b) $\frac{1}{16000} ;(c) \frac{1}{600} ;(d) \frac{1}{25}$. The distance between the start (arrows) and the routine cut (broken line) is $1.5 \mathrm{~cm}$. in each case.

third component immunologically unreactive $(40 \%$ of peak 1). Fig. 10 shows the distribution of 131Ilabelled protein in four strips from this experiment with the Actigraph strip scanner with $2 \pi$ geometry. The blank (no antiserum) shows the presence of a large component centred at the start line and somewhat less electronegative than 131I-labelled growth hormone peak 2 , and a smaller faster component. At an antiserum dilution of $1 / 16000$ all of the smaller faster components had reacted with the antiserum, suggesting that this is immunologically intact but electrophoretically more electronegative growth hormone. At 1/500 much of the slower peak had also reacted with antiserum and at $1 / 25$ this process had gone further. It may be noted that the antibody-bound 131I-labelled protein in this series had travelled less distance towards the cathode than is found for 131I-labelled peak 2 bound to antibody. It seems possible that adsorption to the cellulose acetate may again play a part in this. Alternatively, 
Table 4. Comparison of potencies by immunoassay and distribution on gel filtration of different human growth hormone preparations

Gel filtration was with Sephadex G-200 in borate (0.05 M)- $\mathrm{KCl}(0.05 \mathrm{M}), \mathrm{pH} 8 \cdot 6$.

Potency of

Distribution of eluates as \% of total eluates (by $E_{280}$ or $E_{215}$ )

\begin{tabular}{|c|c|c|c|}
\hline Peak 1 & $\begin{array}{l}\text { Trough } \\
\text { material }\end{array}$ & Peak 2 & $\begin{array}{l}\text { immunoassay as } \% \text { of } \\
\text { laboratory standard } \\
\text { (ICRF batch } 3 \text { ) }\end{array}$ \\
\hline $19 \cdot 6$ & $19 \cdot 1$ & $61 \cdot 2$ & 100 \\
\hline $21 \cdot 2\}$ & $14 \cdot 7\}$ & $64 \cdot 5\}$ & \\
\hline $20 \cdot 8\}$ & $17 \cdot 2\}$ & $61 \cdot 4\}$ & $87 \cdot 4$ \\
\hline $22 \cdot 4$ & $28 \cdot 6$ & $49 \cdot 1^{\prime}$ & $57 \cdot 1$ \\
\hline $12 \cdot 5$ & $18 \cdot 9$ & $68 \cdot 6$ & $80 \cdot 3$ \\
\hline $19 \cdot 1$ & $19 \cdot 1$ & $61 \cdot 8$ & $80 \cdot 6$ \\
\hline $6 \cdot 5$ & $22 \cdot 4$ & $71 \cdot 1$ & $87 \cdot 8$ \\
\hline $4 \cdot 2$ & $12 \cdot 9$ & $82 \cdot 9$ & $\mathbf{8 3 \cdot 8}$ \\
\hline $12 \cdot 8$ & nil & $87 \cdot 2$ & $128 \cdot 8$ \\
\hline
\end{tabular}

this denatured material may be capable of reacting with only one antibody molecule/molecule of antigen. This complex would be more electronegative than the more normal complexes in the region of antibody excess, which consist of several antibody molecules with only one molecule of antigen. These observations confirm the presence of a three-component system in the antigen in this system.

Attempt to improve fractionation of growth hormone on Sephadex columns. In view of the observation from the experiments on batch $4 \mathrm{~b}$ that immunologically inactivated material could still appear in peak 2 from the Sephadex G-200 column in boratepotassium chloride, a systematic attempt was made to improve this separation. This was considerably hampered by failure to understand the mechanism involved in this separation. Small alterations in the pH and molarities of borate or potassium chloride caused considerable alterations in elution pattern, but no improvement in separation of active from inactive components could be obtained. In one case $(0.05 \mathrm{M}$-borate- $0.05 \mathrm{M}$-potassium chloride, pH 8.1) there was a marked shift of the active hormone towards earlier elution.

Distribution of different batches of growth hormone on Sephadex column in borate. Since the separation could not be improved, various preparations were fractionated by using the standard conditions (0.05 M-borate-0.05 M-potassium chloride, pH 8.6) and their distribution was compared with their potencies by radioimmunoassay. The results are tabulated in Table 4. There is but a poor correlation between the potency and relative proportion of peak 2 material present. Thus the two batches of growth hormone kindly supplied by $\mathrm{Dr}$ M. S. Raben had $71.1 \%$ and $82.9 \%$ of peak 2 material but were equipotent with ICRF batch 4, which contained
Table 5. Radioimmunoassay of peak 2 material of Sephadex G-200 column from different batches of growth hormone

\begin{tabular}{|c|c|c|}
\hline & \multicolumn{2}{|c|}{ Potency } \\
\hline & ( $\%$ of unfractionated & ( $\%$ of unfractionated \\
\hline $\begin{array}{l}\text { Source of } \\
\text { peak } 2 \text { material }\end{array}$ & $\begin{array}{l}\text { growth hormone } \\
\text { batch 3; laboratory } \\
\text { standard) }\end{array}$ & $\begin{array}{l}\text { growth hormone } \\
\text { batch from which } \\
\text { prepared) }\end{array}$ \\
\hline ICRF batch 3 & 120 & 120 \\
\hline ICRF batch 4 & 120 & 149 \\
\hline ICRF batch 5 & 108 & 126 \\
\hline
\end{tabular}

$63.0 \%$ of peak 2. The growth hormone prepared by the method of $\mathrm{Li} \&$ Papkoff showed $87 \cdot 2 \%$ of peak 2 material and a higher potency than any one of the six growth hormone batches prepared by Raben's method from acetone-stored pituitaries. However, the $\mathrm{Li} \&$ Papkoff preparation was still heterogeneous. A later preparation from fresh frozen glands in which the Raben procedure was used on the growth hormone-rich fraction $E$ of the procedure of Reisfeld, Lewis, Brink \& Steelman (1962) yielded growth hormone which consisted only of peak 2 material on the borate-potassium chloride Sephadex G-200 column and which (unfractionated) assayed $140 \%$ of the laboratory standard. Table 5 shows the potencies of the most active preparations.

\section{DISCUSSION}

Biological assays for hormones can be established when the standard preparations used are chemically quite impure. Indeed, such a standard may consist largely of hormonally inactive material. The presence of other hormones in such a standard also can be tolerated provided that the bioassay itself 
can be shown not to respond to the contaminants. Immunological methods, however, require the availability of standard preparations approaching $100 \%$ purity, since contaminating proteins must be expected to be antigenic. Immunoassays depending upon homogeneity of antiserum (precipitin reaction, haemagglutination inhibition) impose an excessive stringency with respect to the homogeneity of the antigen used, since antibodies may be raised in high titre to small quantities of highly antigenic contaminants. It may be noted that an antiserum raised to one growth hormone preparation in which no albumin could be detected physicochemically, and which was subsequently found by immunoassay to contain less than $2 \%$ of albumin, had a slightly higher titre as an antiserum to human plasma albumin than as an antiserum to growth hormone. Antibodies to contaminants not originating in the same gland as the specific hormone (e.g. plasma proteins) may be removed by absorption, but this method cannot so readily be used where the contaminants do originate in the same organ. Where it can be so used, it is limited to the removal of antibodies to known proteins, themselves available in highly purified form.

The radioimmunoassay method, however, depends for its specificity solely upon the homogeneity of the hormone preparation used for labelling with radioiodine, whilst less purified preparations may be used as antigen and as standards (Hunter \& Greenwood, 1964). The availability of small quantities of a homogeneous preparation of the hormone is thus a prerequisite for the establishment of such an assay.

Human growth hormone prepared by the method of Raben contains a single antigen, as shown by immunodiffusion (Grumbach \& Kaplan, 1962). Though appearing homogeneous in free-boundary electrophoresis, the greater discrimination of starch-gel (Ferguson \& Wallace, 1961) and polyacrylamide-gel electrophoresis (Reisfeld et al. 1963) shows the preparation to consist of a series of proteins. Immunoelectrophoresis has shown that these subfractions are immunologically identical (Grumbach \& Kaplan, 1962) and these have also been shown to possess similar biological activity by metabolic studies in man (Laron \& Assa, 1962) and by the tibia test (Laron, Assa \& Menache, 1963). These findings must be regarded as qualitative since quantitative elution from agar gel cannot be guaranteed, and the biological systems used were imprecise. The present study has shown heterogeneity by using starch-grain electrophoresis, which discriminates on a basis purely of charge. Studies using Sephadex for gel diffusion in buffers other than those containing borate failed to detect any heterogeneity of molecular size. These data suggest that the heterogeneity shown in gel electrophoresis and immunoelectrophoresis is due to variations in charge rather than molecular size in the subfractions. With polyacrylamide-gel electrophoresis, Lewis (1962) on human growth hormone prepared by the method of Lewis \& Brink (1958) showed the progressive formation, on incubation, of faster components at the expense of the major less electronegative band. These changes were shown to be due to the action of protease enzymes present in the pituitary gland (Adams \& Smith, 1951) and as contaminants of the growth hormone preparations, since they could be prevented by including the enzyme inhibitor di-isopropyl phosphorofluoridate in the incubated mixture.

The use of Sephadex G-200 in a borate-containing buffer has facilitated a better separation of the altered and more electronegative components, and this can be achieved on a preparative scale. Combination of this separation with the very precise radioimmunoassay procedure has enabled the alterations undergone by growth hormone to be put on a firm quantitative basis. The column system used has allowed a marginal purification of growth hormone prepared from acetone-stored pituitary glands by the Raben procedure to give potencies between $110 \%$ and $150 \%$ of the unfractionated preparations.

The reaction of radioiodinated subfractions of growth hormone with antiserum to the whole preparation has indicated the presence in growth hormone prepared by the Raben procedure of subfractions having differing charge but identical affinity for antiserum, of a fraction having greatly reduced affinity for antiserum and of a further fraction which is completely unreactive towards the antiserum. This would appear to be the only procedure at present available which is capable of detecting the presence of immunologicaly inert material in a protein preparation. Only the immunologically intact fraction of these growth hormone preparations is measured in the radioimmunoassay, and a biological assay carried out on subfractions of one preparation showed excellent agreement between the two methods.

When unfractionated growth hormone (ICRF batch 3) was used for labelling with radioiodine, only $80 \%$ of the preparation was bound to antibody in excess of antiserum. When the active subfraction (peak 2) of this same batch was radioiodinated, 95\% was so bound. The presence of immunologically inert radioactive material in the incubated mixture of a radioimmunoassay does not of itself matter since this component should remain in the 'free' or unbound fraction of the separative system used. However, the inert fraction from growth hormone adsorbs strongly and also shows a greater tendency to interaction with other proteins than does the active hormone. The effect of such interaction which may occur with plasma proteins will depend 
upon the system used to separate the antibodybound from the 'free' radioiodinated growth hormone. In the immunoprecipitation method (Utiger, Parker \& Daughaday, 1962) such interaction might be the cause of the falsely high values found for growth hormone in unextracted plasma. In the chromatoelectrophoretic system employed by Glick et al. (1963), interaction of the inert fraction of the labelled hormone with plasma proteins would result in its transfer to the 'bound ' area. This would tend to cause falsely low results in this assay. The authors correct their results to allow for this effect and they also purify their 131I-labelled growth hormone by starch-gel electrophoresis subsequent to radioiodination. In the electrophoretic system of Hunter \& Greenwood (1964) the inert fraction tends to spread slightly into the 'bound' area. This process is enhanced by plasma so that slightly lower than true values were obtained for growth hormone in plasma when the unfractionated growth hormone was earlier used for labelling and use in the assay. More recently the purified (Sephadex G-200 peak 2) fraction has been used and this effect was insignificant.

The use of the highly purified fraction as standards in the immunoassay is not necessary. This fraction gives an inhibition curve which is parallel to that from the unfractionated material when the logarithm of their concentration is plotted against percentage of the labelled hormone bound to antibody. This parallelism has been found for all pituitary fractions tested. Thus human growth hormone preparations can be assayed one against another and expressed as percentage potencies of a standard preparation. The present availability of a standard preparation (Medical Research Council human growth hormone standard A) will enable results in different Laboratories to be compared. Ultimately, it must be expected that a preparation consisting only of the fully active hormone will become available. The separative ability of the Sephadex G-200 column in borate-potassium chloride here described is not adequate for this task. Further, there would appear to be no method available at present for recognizing such a preparation. All that can be said is that the most potent preparations reach the nearest to this goal.

I acknowledge the help and co-operation of Dr F. C. Greenwood throughout this work. I am grateful also for the encouragement of Dr G. F. Marrian. I thank Miss M. Pritchard for technical assistance.

\section{REFERENCES}

Adams, E. \& Smith, E. L. (1951). J. biol. Chem. 191, 651. Barrett, R. J., Friesen, H. \& Astwood, E. B. (1962). J. biol. Chem. 237, 432.

Boucher, B. J. (1960). Nature, Lond., 188, 1025.

Dixon, J. S. \& Li, C. H. (1962). J.gen. Physiol. 45, 136.

Eastoe, J. E. (1955). Biochem. J. 61, 589.

Ferguson, K. A. \& Wallace, A. L. C. (1961). Nature, Lond., $190,629$.

Flodin, P. (1961). J. Chromat. 5, 103.

Gelotte, B. (1960). J. Chromat. 3, 330.

Glick, S. M., Roth, J., Yalow, R. S. \& Berson, S. A. (1963). Nature, Lond., 199, 784.

Greenwood, F. C., Hunter, W. M. \& Glover, J. S. (1963). Biochem. J. 89, 114.

Grumbach, M. M. \& Kaplan, S. L. (1962). Ciba Found. Colloq.: Endocrinology, 14, 63.

Hunter, W. M. (1963). Analyst, 88, 251.

Hunter, W. M. \& Greenwood, F. C. (1962). Biochem. J. 85, $39 \mathrm{P}$.

Hunter, W. M. \& Greenwood, F. C. (1964). Biochem. J. 81, 43.

Irie, M. \& Barrett, R. J. (1962). Endocrinology, 71, 277.

Kunkel, H. G. \& Slater, R. J. (1952). Proc. Soc. exp. Biol., N.Y., 80, 42.

Laron, Z. \& Assa, S. (1962). Nature, Lond., 194, 491.

Laron, Z., Assa, S. \& Menarche, R. (1963). J.clin. Endocrin. 23, 315.

Lewis, U. J. (1962). J. biol. Chem. 237, 3141.

Lewis, U. J. \& Brink, N. G. (1958). J. Amer. chem. Soc. 80, 4429.

Li, C. H. (1964). Experientia, 20, 169.

Li, C. H. \& Papkoff, H. (1956). Science, 124, 1293.

Lowry, O. H., Rosebrough, N. J., Farr, A. L. \& Randall, R.J. (1951). J. biol. Chem. 193, 265.

Meisinger, M. A. P., Cirillo, V. J., Davis, G. E. \& Reisfeld, R. A. (1964). Nature, Lond., 201, 820.

Moore, S. \& Stein, W. H. (1951). J. biol. Chem. 192, 663.

Raben, M. S. (1959). Recent Progr. Hormone Res. 15, 71.

Read, C. H. \& Bryan, G. T. (1960). Ciba Found. Colloq.: Endocrinology, 13, 68.

Read, C. H. \& Stone, D. B. (1958). Amer. J. Dis. Childh. 86, 538.

Reisfeld, R. A., Hallows, B. G., Williams, D. E., Brink, N. G. \& Steelman, S. L. (1963). Nature, Lond., 197, 1206.

Reisfeld, R. A., Lewis, U. J., Brink, N. G. \& Steelman, S. L. (1962). Endocrinology, 71, 559.

Squire, P. G. \& Pedersen, K. O. (1961). J. Amer. chem. Soc. 83, 476.

Utiger, R. D., Parker, M. L. \& Daughaday, W. H. (1962). J. clin. Invest. 41, 254. 